\title{
DETERMINATION OF KEPONE AND ITS METABOLITE IN WATER AND SOIL BY HIGH-PERFORMANCE LIQUID CHROMATOGRAPHY - MASS SPECTROMETRY
}

Dahai Hea,b, Bing Xia ${ }^{a}$, Jun Liub ${ }^{b}$ Lisheng Ding ${ }^{a}$, Yan Zhou*,a

${ }^{a}$ Chengdu Institute of Biology, Chinese Academy of Sciences, Chengdu 610041, People's Republic of China, No.9 Section 4,Renmin Nan Road,Chengdu, Sichuan, P.R. China. Email: zhouyan@cib.ac.cn

${ }^{\mathrm{b} C o l l e g e}$ of Chemistry \& Environment Protection Engineering, Southwest University for Nationalities, Chengdu 610041, China

\section{SUPPLEMENTAL MATERIAL}

Figure S1. Full-scan total ion chromatogram of kepone $(1 \mu \mathrm{g} / \mathrm{mL})$ in methanol.

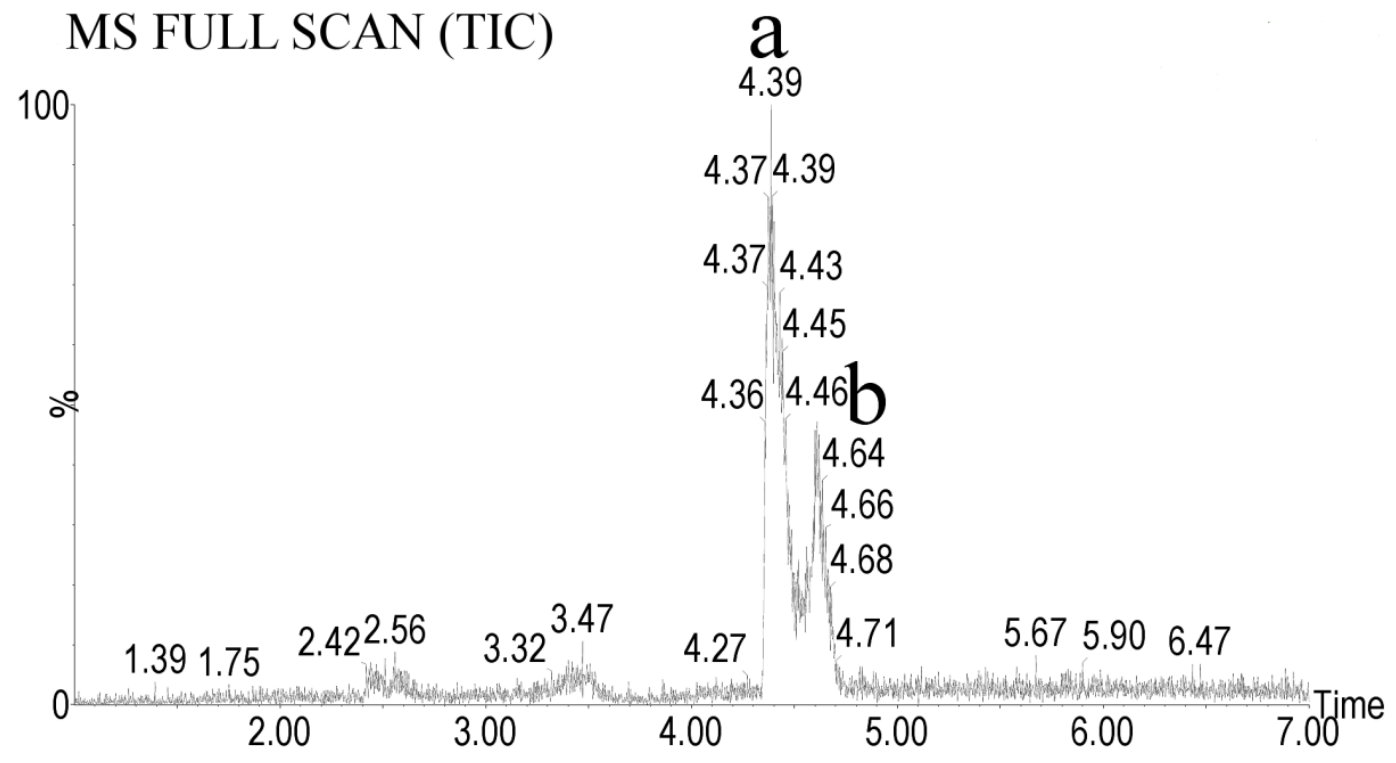


Figure S2. Electrospray ionization mass spectra of (a) kepone hydrate and (b) kepone alcohol corresponding to Figure S1.
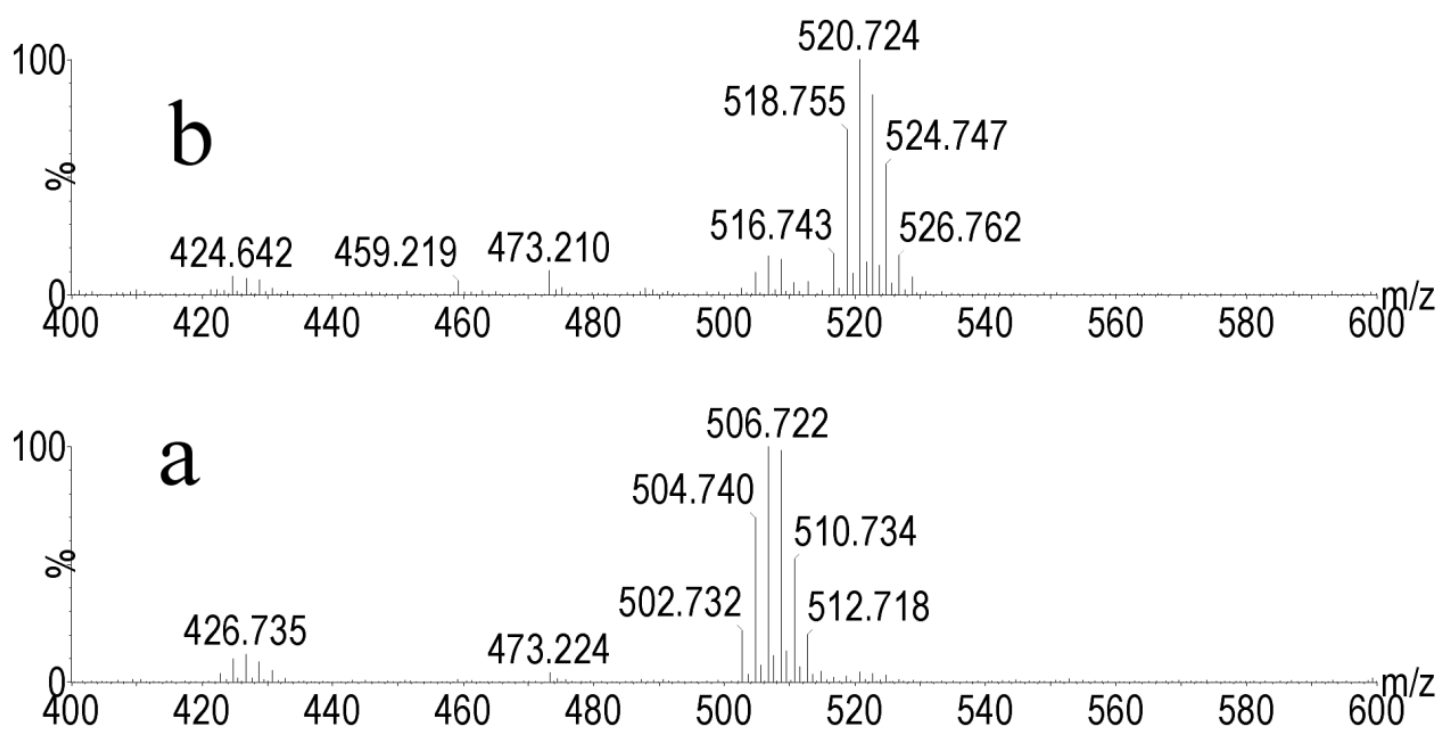

Figure S3. The formation of kepone hydrate.

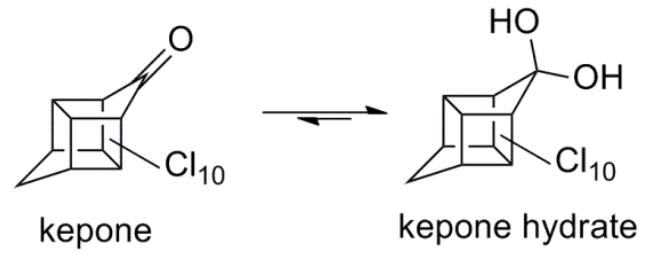

Figure S4. The formation of methanolic hemiketal.

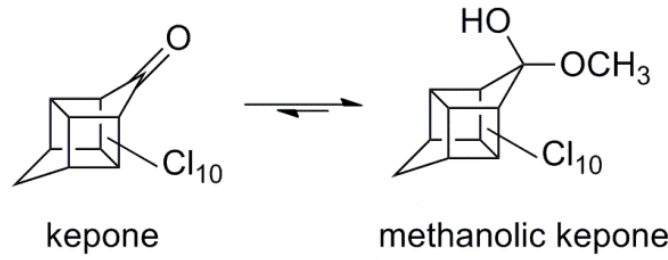


Figure S5. Kepone hydrate and kepone alcohol in water.
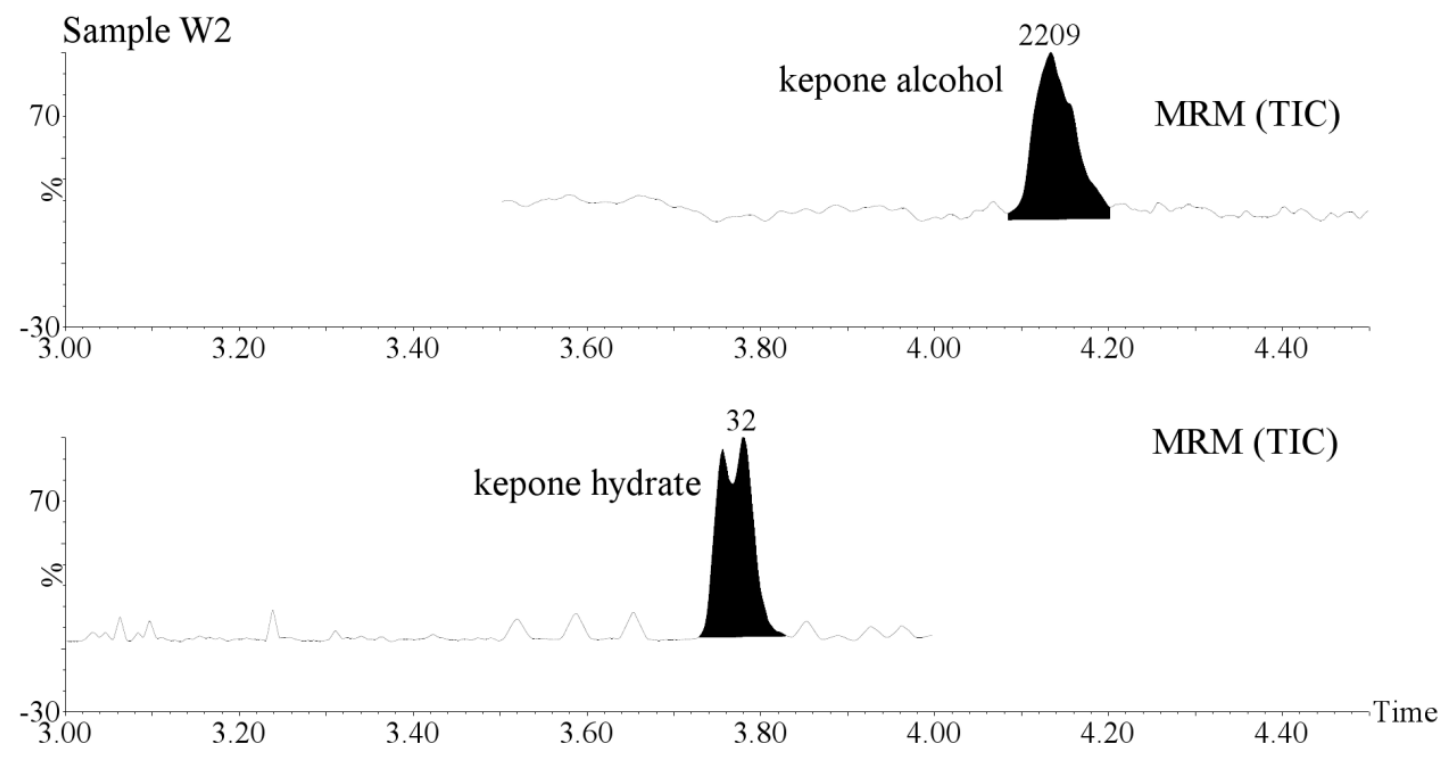

Figure S6. Kepone hydrate and kepone alcohol in soil.

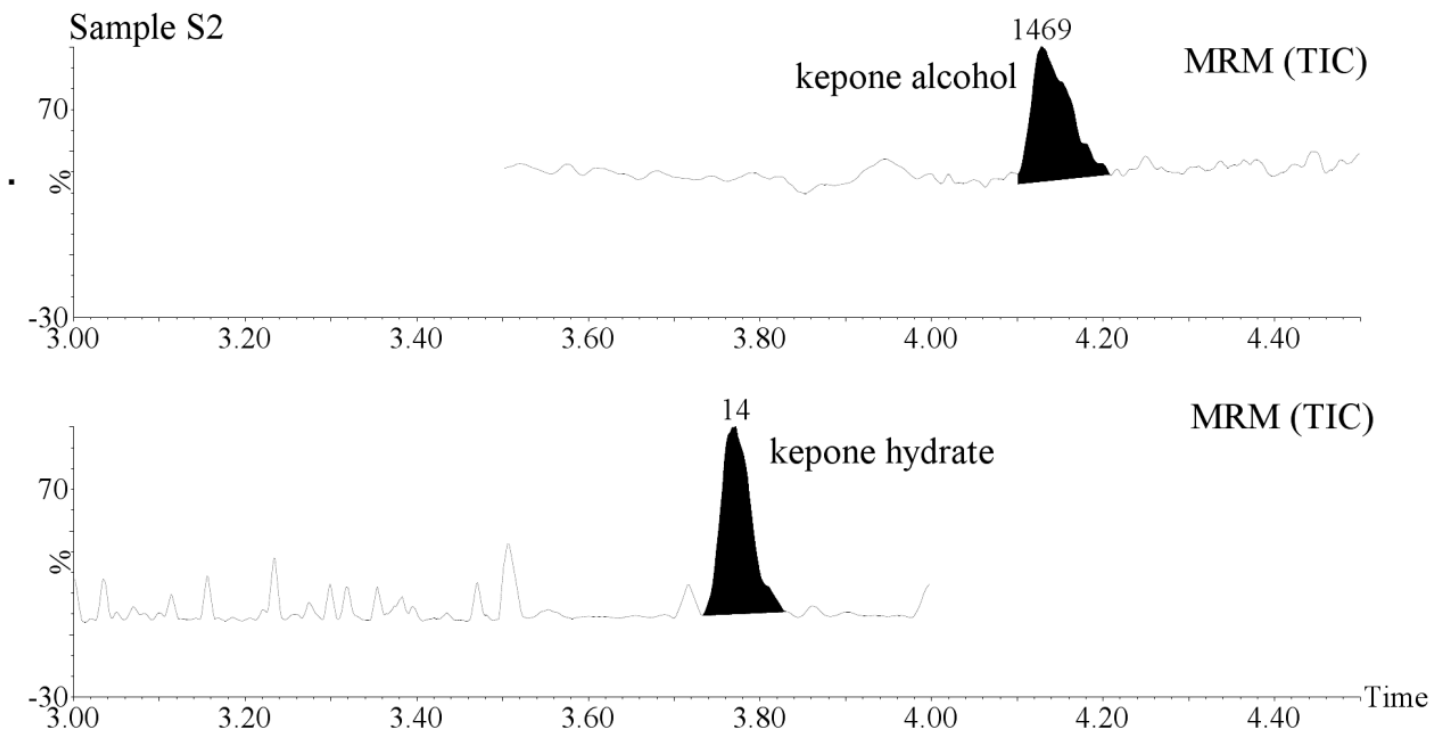

